УДК 002.2

DOI: $10.17223 / 22220836 / 28 / 21$

\title{
О.Л. Лаврик
}

\section{КОЛЛЕКТИВНЫЕ МОНОГРАФИИ: ПОПЫТКА ФОРМАЛИЗОВАННОЙ ОЦЕНКИ НАУЧНОЙ ЦЕННОСТИ ${ }^{1}$}

\begin{abstract}
В статье предпринята попытка определить по формальным признакам содержательный уровень научных коллективных монографий. Сравнительный анализ ряда коллективных монографий по ряду формальных характеристик показал, что таковыми могут быть следуюшие: кто является инициатором подготовки коллективной монографии; на какие средства она издается; есть ли социтирование и соавторство авторов монографии в других публикацих; есть ли книга в фондах библиотек, получающих обязательный экземпляр. Предлагается включать их в издательскую аннотацию.

Ключевые слова: коллективная монография, формальные характеристики, издательства, издательская коллективная монография, соавторство, соиитирование, открытый доступ, обязательный экземпляр.
\end{abstract}

\section{Введение}

Проблема качества научных публикаций в последние годы стала все активнее обсуждаться в специальной литературе.

О серьезных проблемах журнальных публикациях писали многие авторы (например, Ю. Кравиар и М. Хладик [1], Е.Г. Абрамов [2]]. Е.В. Угринович с соавт. в работе [3] привели «восхитительные» данные о росте количества научных издательств и журналов, готовых публиковать за деньги недостоверную и нерецензируемую информацию. Широко известны размещенные в Интернете списки недобросовестных журналов открытого доступа (проект Дж. Билла). Появились даже списки баз данных, продвигающих эти журналы. Не зря РИНЦ выделил из своего общего каталога журналов ряд спамовых изданий и публикаций, подробно прокомментировав этот акт [4]. Появился новый термин - predatory publishers и predatory journals - хищные (в другом переводе - грабительские) издательства и журналы.

Результаты изучения еще одного вида научной нерецензируемой литературы - материалов заочных конференций, пустивших корни в издательской среде, особенно электронной, приведены в работах [5-8].

А как обстоят дела с монографиями, особенно коллективными? Научная книга, монография всегда считались важнейшим способом формальных научных коммуникаций. Для многих ученых нашей страны бренд издательства (например, «Наука» и его отделений, Springer, Elsevier) служил эталоном качества содержания научного издания. Автоматически считалось, что если монография издана в «Науке», то она содержит новые научные знания.

О бренде издательства знали и читатели, и библиотекари. Но сейчас издательств появилось огромное множество. Одна из проблем - как отличить

\footnotetext{
${ }^{1}$ Работа выполнена в рамках комплексной программы СО РАН ІІ.2П «Интеграция и развитие».
} 
хищническое издательство от традиционного? Как понять, имеет ли дело комплектатор, создатель информационного ресурса, читатель или заинтересованный пользователь, проведший поиск в универсальной базе данных, с действительно научной публикаций или найденный опус (по названию, аннотации или ключевым словам так соответствующий информационной потребности!) написан исключительно для повышения публикационной активности, для создания имиджа и т.д., но не содержит новых результатов научных исследований?

Если в журнальной публикации можно сразу выделить спамовые черты, опираясь на такие особенности, как оплата публикации статьи ${ }^{1}$ и очень бblстрое издание (т.е. фактическое отсутствие рецензирования), то с монографией все не так очевидно. За издание монографии автор (или его организация, будь он один или целый авторский коллектив) всегда платит издательству, если только организация, где работают авторы, не имеет собственного редакционно-издательского отдела и полиграфической базы (т.е. в этом случае тоже платит организация). На публикацию своего труда автор (авторы) могут получить и грант (РФФИ, ГРНФ и др.).

Если оценить научный уровень монографии с одним-двумя авторами в любом случае сможет только эксперт в определенной области, то по каким формальным признакам следует очень осторожно отнестись к научным выводам, изложенным в коллективной научной монографии? Или по каким формальным параметрам мог бы судить специалист-читатель, комплектатор библиотеки, информационный работник, формирующий тематический или проблемно ориентированный ресурс, что за издание перед ним, несмотря на интересную и профильную аннотацию, наличие главного редактора и рецензентов?

Попробуем ответить на этот вопрос.

\section{1. Монография как научный продукт}

История появления и развития научной книги уже достаточно хорошо описана в книговедческих и науковедческих работах $[9,10]$. И несмотря на то, что ГОСТ на термин «научная книга» и тем более «научная монография» и «коллективная монография» (так же как научная книга) отсутствует, есть сложившееся понимание и несколько достаточно близких, определений понятия «монография» и «научная книга»:

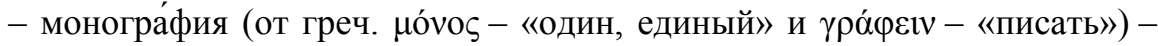
научный труд в виде книги с углублённым изучением одной темы или нескольких тесно связанных между собой тем [11];

- монография - это научный труд, наиболее полным образом раскрывающий сущность одной или нескольких взаимосвязанных тематик;

- «научная книга - это основной источник фундаментальных научных знаний и основной образовательный ресурс. В ней концентрируются резуль-

${ }^{1} \mathrm{C}$ сожалением автор вынужден констатировать, что «платной» стала публикация и в традиционных журналах с хорошей научной репутацией. По личному опыту (специальность ВАК 05.25.03) знаем, что только за плату можно опубликоваться в таких журналах, как «Вестник КазГУКИ», «Вестник ЧГАКИ», «Вестник КемГУКИ». 
таты глубоких, порой многолетних, исследований, методики, оценки стратегических направлений в развитии различных отраслей знания» [12];

- научная книга - это «важнейшее средство обобщения научной информации, содержащее результаты теоретических и(или) экспериментальных исследований, а также научно подготовленные к публикации памятники культуры и исторические документы. В научных книгах публикуются теоретические исследования, освещается опыт, достигнутый в тех или иных областях практической деятельности, разрабатываются стратегические проблемы науки, хозяйства и культуры [13].

В качестве рабочего определения исходя из целей статьи будем считать, что коллективная монография (научная книга) - это научный труд, отражающий результаты исследований теоретического, прикладного, прогнозного или методического характера, проведенного группой исследователей, работающих в одном учреждении или временном коллективе по заранее принятой программе научных исследований ${ }^{1}$.

Традиционные монографии обычно делятся на экспериментальные и аналитические ${ }^{2}$, научные и практические ${ }^{3}$, имеют определенный объем (не менее 7-10 а.л.), тираж (не менее 300 экз.) и определенную структуру (наличие титульного листа (обложки), аннотации, оглавления, вводной главы, содержательной части, заключения и списка литературы со списком условных обозначений), наличие как минимум двух рецензий экспертов с научной степенью из изучаемой автором сферы науки.

Выдвинем гипотезу, что формальные различия между истинно научной коллективной монографией и таковой, не несущей новых научных знаний, т.е. написанной исключительно для повышения публикационной активности и для создания имиджа, следует искать на основе сравнения следующих пар характеристик:

1. Издательство не приглашает (приглашает) присылать материалы для издания коллективной монографии в рамках заданной тематики.

2. Авторы монографии работают в одном, двух или большем количестве учреждений.

3. Авторы коллективной монографии работают (не работают) по одному проекту (программе).

4. Авторы имеют (не имеют) совместные публикации, ссылаются (не ссылаются) на работы друг друга.

5. Монографии представлены (не представлены) в открытом доступе (ОД).

6. Монографии есть (отсутствуют) в фондах библиотек, получающих обязательный экземпляр (ОЭ) (отражены в электронных каталогах (ЭК).

\footnotetext{
${ }^{1}$ В это определение не вписываются опубликованные результаты научного труда ученогоодиночки, имеющего свою собственную исследовательскую программу. Но монографии, изданные под именем одного или двух авторов в данной работе не рассматриваются.

${ }^{2}$ В экспериментальной монографии автор подводит итог своего эксперимента, опыта, обобщая свой научный вклад в определённую сферу знаний. Аналитическая предполагает тщательное теоретическое изучение тематики, выявление существующих тенденций, мнений в научном сообществе и формулирование собственных, новых идей и гипотез автором.

${ }^{3}$ Научные монографии (как и аналитические в предложенной выше классификации) подразумевают под собой именно теоретическое исследование теорий, взглядов и мнений экспертов с целью формирования нового первичного научного знания. Однако практические монографии в этом случае предназначены для раскрытия главной мысли и идеи диссертации на соискание научной степени.
} 


\section{2. Отбор материала для исследования}

Опираясь на эти формальные признаки, а также на рабочее определение понятия «научная монография», нами были отобраны коллективные научные монографии (работы, написанные более чем двумя авторами), изданные в 2013-2026 гг. ${ }^{1}$ тремя группами издающих организаций:

1) научными издательствами (Наука, Техносфера, ФИЗМАТЛИТ), имеющими хорошую научную репутацию [13];

2) издательствами, «зарекомендовавшими» себя изданием спамовых журналов (рис. 1) и издающими также и монографии (Научное обозрение, Научный мир, Консалтинговая компания Юком) ${ }^{2}$;

3) научными институтами и вузами, имеющими свою полиграфическую базу: Издательство института философии РАН, Издательство института русской литературы, Издательство Государственной публичной научнотехнической библиотеки (ГПНТБ) СО РАН, Издательство Новосибирского государственного технического университета.

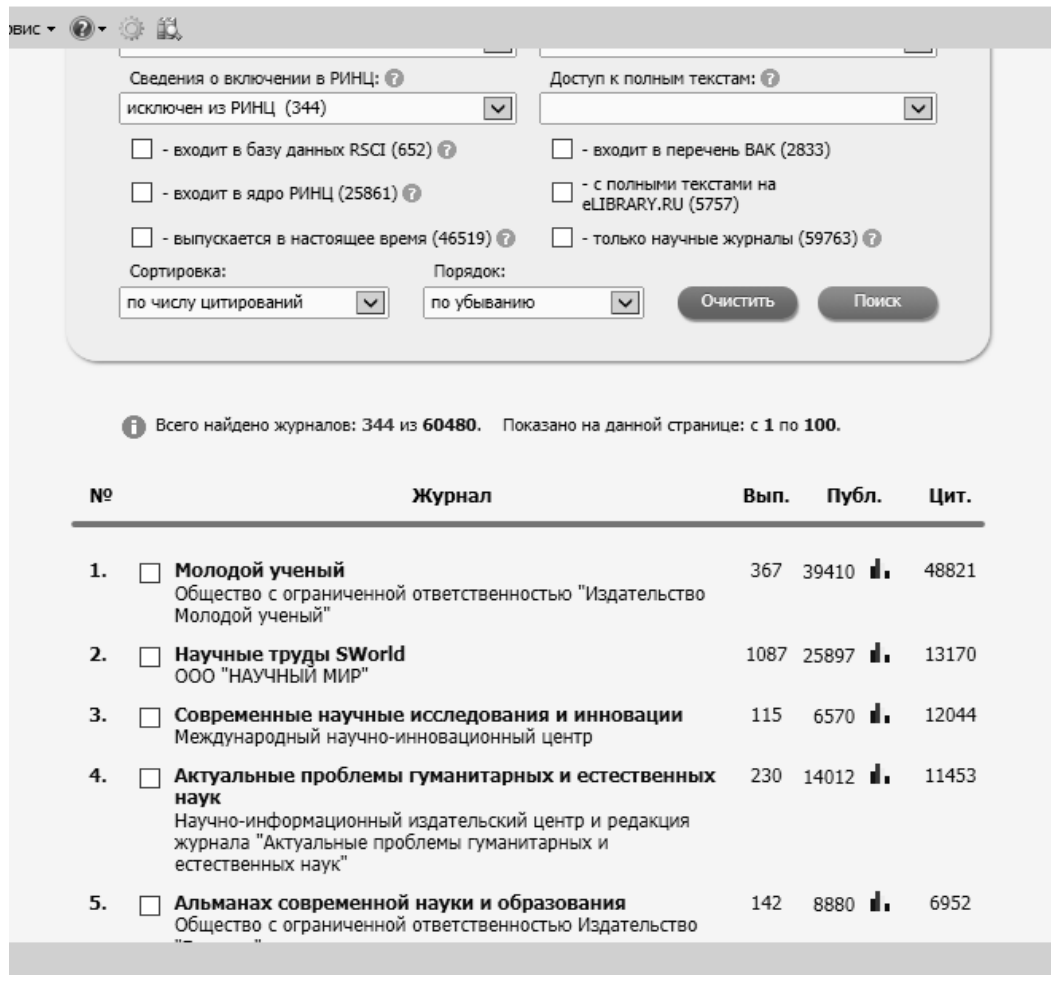

Рис. 1. РИНЦ как источник информации для определения издательств

\footnotetext{
${ }^{1}$ Данный отрезок времени был выбран для того, чтобы все издательства оказались в равных временных рамках.

${ }^{2}$ Отметим, что в статье отражен уже окончательный список издательств. Изначально был составлен список из более чем 20 издательств и выяснено, публикуют ли они монографии. Оказалось, например, что издательство «Молодой ученый» публикует, помимо журналов, только материалы конференций, «Грамота» - только журналы и т.д.
} 
Для получения необходимых характеристик были проанализированы сайты издательств, издающих организаций, проведены поиски в РИНЦ и ЭК ГПНТБ СО РАН (как библиотеке, получающей обязательный экземпляр), выполнен содержательный анализ издательских аннотаций.

Кроме того, было принято во внимание, что при оценке публикационной активности организаций на основе индекса Хирша более всего в гуманитарной области цитируются именно монографии (табл. 1, 2). В естественнонаучной же области топовые места в рейтинге публикаций организации занимают статьи в зарубежных журналах (табл. 3).

\section{Таблица 1. Топовые по цитированию публикации, формирующие h-индекс ГПНТБ СО РАН}

\begin{tabular}{|c|c|c|}
\hline $\begin{array}{c}\text { № } \\
\Pi / \Pi\end{array}$ & Наименование публикации & $\begin{array}{l}\text { Количе- } \\
\text { ство } \\
\text { ссылок }\end{array}$ \\
\hline 1 & $\begin{array}{l}\text { Очерки истории книжной культуры Сибири и Дальнего Востока. } \\
\text { Пайчадзе С.А., Волкова В.Н., Гузнер И.А., Маслова А.Н. Государст- } \\
\text { венная публичная научно-техническая библиотека СО РАН. Ново- } \\
\text { сибирск, 2000. Том } 1 \text { Конец XVIII - середина 90-х годов XIX в. }\end{array}$ & 117 \\
\hline 2 & $\begin{array}{l}\text { Метод Монте-Карло в атмосферной оптике, Марчук Г.И., Михайлов } \\
\text { Г.А., Назаралиев М.А., Дарбинян Р.А., Каргин Б.А., Елепов Б.С. Но- } \\
\text { восибирск, } 1976 .\end{array}$ & 100 \\
\hline 3 & $\begin{array}{l}\text { Книга в России, 1881-1895. Фролова И.И., Патрушева Н.Г., Грин- } \\
\text { ченко Н.А., Кельнер В.Е., Люблинский С.Б., Ансберг О.Н., Белов С.В., } \\
\text { Горшков Ю.А., Горбунов Ю.А., Кильдюшевская Л.К., Блюм А.В., } \\
\text { Рейтблат А.И., Аверина Н.Ф., Волкова В.Н., Пайчадзе С.А., и др. } \\
\text { Под общей редакцией И.И. Фроловой; Санкт-Петербург, 1997. }\end{array}$ & 94 \\
\hline 4 & $\begin{array}{l}\text { Академическая библиотека в современной информационной среде. } \\
\text { Лаврик О.Л. Государственная публичная научно-техническая биб- } \\
\text { лиотека СО РАН. Новосибирск, } 2003 .\end{array}$ & 50 \\
\hline 5 & $\begin{array}{l}\text { Книга в России, 1861-1881. Немировский Е.Л., Горшков Ю.А., Бе- } \\
\text { лов С.В., Патрушева Н.Г., Шпак А.П., Аверина Н.Ф., Волкова В.Н. } \\
\text { М., 1990. Том } 2\end{array}$ & 50 \\
\hline 6 & $\begin{array}{l}\text { Сибирское книгоиздание второй половины ХІХ В. Волкова В.Н. } \\
\text { Новосибирск, } 1995 .\end{array}$ & 46 \\
\hline 7 & $\begin{array}{l}\text { Книжное дело на Дальнем Востоке. Дооктябрьский период. Пай- } \\
\text { чадзе С.А. ГПНТБ СО АН СССР. Новосибирск, } 1991 .\end{array}$ & 41 \\
\hline 8 & $\begin{array}{l}\text { Библиотека в системе общественных отношений региона. Артемье- } \\
\text { ва Е.Б., Жданова Т.А., Кожевникова Л.А., Маслова А.Н. Новоси- } \\
\text { бирск, } 1999\end{array}$ & 41 \\
\hline 9 & $\begin{array}{l}\text { Археологический портал знаний: содержательный доступ к знаниям } \\
\text { и информационным ресурсам по археологии. Андреева О.А., Боро- } \\
\text { викова О.И., Булгаков С.В., Загорулько Ю.А., Сидорова Е.А., Цир- } \\
\text { кин Б.Г., Холюшкин Ю.П. // КИИ-2006 10-я национальная конфе-- } \\
\text { ренция по искусственному интеллекту с международным участием. } \\
\text { РАИИинтеллекта. 2006. С. 832-840. }\end{array}$ & 38 \\
\hline 10 & $\begin{array}{l}\text { Природоохранное законодательство развитых стран. Лебедева А.Н., } \\
\text { Лаврик О.Л. Аналитический обзор : в } 3 \text { частях / Государственная } \\
\text { публичная научно-техническая библиотека СО РАН; отв. ред. } \\
\text { М.А. Грачев. Новосибирск, } 1992 \text { (Сер. Экология. Вып. 27). }\end{array}$ & 35 \\
\hline
\end{tabular}


Таблица 2. Первое место в рейтинге публикаций в гуманитарных НИУ

\begin{tabular}{|c|c|c|c|c|}
\hline $\begin{array}{c}\text { № } \\
\Pi / \Pi\end{array}$ & НИУ & Рейтинг. Вид издания & Цитирований & Год изд. \\
\hline \multirow[t]{3}{*}{1} & \multirow{3}{*}{$\begin{array}{l}\text { Ин-т истории и } \\
\text { археологии УрО } \\
\text { РАН }\end{array}$} & 1. Монография & 522 & 1995 \\
\hline & & 12. Статья в Nature & 104 & 2015 \\
\hline & & 28. Статья в журнале & 80 & 2000 \\
\hline \multirow[t]{3}{*}{2} & \multirow{3}{*}{$\begin{array}{l}\text { Ин-т археологии } \\
\text { и этнографии } \\
\text { СО РАН }\end{array}$} & 1. Статья в Nature & 608 & 2010 \\
\hline & & 2. Статья в Science & 455 & 2015 \\
\hline & & 3. Монография & 387 & 1985 \\
\hline \multirow[t]{2}{*}{3} & \multirow[t]{2}{*}{$\begin{array}{l}\text { Ин-т филологии } \\
\text { СО РАН }\end{array}$} & $\begin{array}{l}\text { 1. Словарь (= коллективная } \\
\text { моногафия) } \\
\end{array}$ & 825 & 1969 \\
\hline & & 22. Статья в сборнике & 95 & 1986 \\
\hline \multirow[t]{2}{*}{4} & \multirow{2}{*}{$\begin{array}{l}\text { Ин-т рус. лите- } \\
\text { ратуры (Пуш- } \\
\text { кинский Дом) } \\
\end{array}$} & 1. Монография & 768 & 1980 \\
\hline & & 15. Статья в сборнике & 53 & 1978 \\
\hline \multirow[t]{3}{*}{5} & \multirow{3}{*}{$\begin{array}{l}\text { Ин-т славянове- } \\
\text { дения РАН }\end{array}$} & 1. Монография & 1331 & 1995 \\
\hline & & $\begin{array}{l}\text { 3. Статья в сборнике (тот } \\
\text { же автор) } \\
\end{array}$ & 925 & 1983 \\
\hline & & 82. Статья в журнале & 129 & 2001 \\
\hline \multirow[t]{2}{*}{6} & \multirow[t]{2}{*}{$\begin{array}{l}\text { Ин-т рус. яз. } \\
\text { РАН }\end{array}$} & $\begin{array}{l}\text { 1. Словарь (коллективная } \\
\text { монография) }\end{array}$ & 2152 & 1997 \\
\hline & & 7. Статья в журнале & 882 & 1995 \\
\hline \multirow[t]{2}{*}{7} & \multirow{2}{*}{$\begin{array}{l}\text { Ин-т истории } \\
\text { СО РАН }\end{array}$} & 1. Монография & 261 & 1991 \\
\hline & & 38. Статья в сборнике & 32 & 2001 \\
\hline \multirow[t]{2}{*}{8} & \multirow{2}{*}{$\begin{array}{l}\text { Ин-т философии } \\
\text { и права СО РАН }\end{array}$} & 1. Монография & 870 & 1995 \\
\hline & & 8. Статья в журнале & 74 & 2007 \\
\hline \multirow[t]{2}{*}{9} & \multirow{2}{*}{$\begin{array}{l}\text { Ин-т философии } \\
\text { и права УрО } \\
\text { РАН }\end{array}$} & 1. Монография & 2558 & 1999 \\
\hline & & 39. Статья в журнале & 142 & 1992 \\
\hline
\end{tabular}

Таблица 3. Виды публикаций, имеющие 1-е место в рейтинге изданий научной организации в области естественных наук

\begin{tabular}{|c|l|c|c|c|}
\hline $\begin{array}{c}\text { № } \\
\text { п/ п }\end{array}$ & \multicolumn{1}{|c|}{ НИУ } & Вид издания & Цитирований & $\begin{array}{c}\text { Год публи- } \\
\text { кации }\end{array}$ \\
\hline 1 & \multicolumn{1}{|c|}{2} & 3 & 4 & 5 \\
\hline 1 & $\begin{array}{l}\text { Объединенный ин-т ядер- } \\
\text { ных исследований }\end{array}$ & $\begin{array}{l}\text { Статья в зару- } \\
\text { бежном жур- } \\
\text { нале }\end{array}$ & 3249 & 2012 \\
\hline 2 & $\begin{array}{l}\text { Ин-т теоретической и экс- } \\
\text { периментальной физики }\end{array}$ & «щ« & 3249 & 2012 \\
\hline 3 & $\begin{array}{l}\text { Физический ин-т им. Лебе- } \\
\text { дева РАН }\end{array}$ & «щ« & 3249 & 2012 \\
\hline 4 & $\begin{array}{l}\text { Ин-т физики высоких энер- } \\
\text { гий }\end{array}$ & «щщ & 4842 & 2012 \\
\hline 5 & $\begin{array}{l}\text { Ин-т ядерной физики СО } \\
\text { РАН }\end{array}$ & «щщ & 8409 & 2003 \\
\hline
\end{tabular}


Окончание табл. 3

\begin{tabular}{|c|c|c|c|c|}
\hline 1 & 2 & 3 & 4 & 5 \\
\hline 6 & $\begin{array}{l}\text { Петербургский ин-т ядер- } \\
\text { ной физики РАН }\end{array}$ & ««" & 3249 & 2012 \\
\hline 7 & Ин-т ядерных исследований & ««《! & 3227 & 2012 \\
\hline 8 & $\begin{array}{l}\text { ФИЦ Институт прикладной } \\
\text { математики РАН }\end{array}$ & ««" & 2511 & 1973 \\
\hline 9 & $\begin{array}{l}\text { Ин-т физики твердого тела } \\
\text { РАН }\end{array}$ & ««世 & 1219 & 2004 \\
\hline 10 & $\begin{array}{l}\text { Физико-технический ин-т } \\
\text { им. Иоффе }\end{array}$ & ««《 & 1433 & 2009 \\
\hline
\end{tabular}

Результаты отбора и систематизации материала представлены в табл. 4.

Таблица 4. Формальная характеристика коллективных монографий различных групп издательств

\begin{tabular}{|c|c|c|c|c|c|c|c|}
\hline \multirow[b]{2}{*}{$\begin{array}{l}\text { F } \\
\text { 要 } \\
\text { 일 }\end{array}$} & \multirow[b]{2}{*}{ 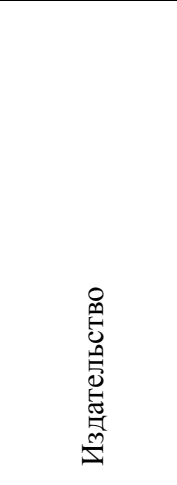 } & \multirow[b]{2}{*}{ 丞 } & \multicolumn{5}{|c|}{$\begin{array}{c}\text { Характерные черты издательств } \\
\text { и коллективных монографий }\end{array}$} \\
\hline & & & 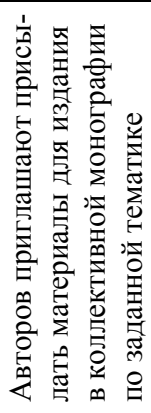 & 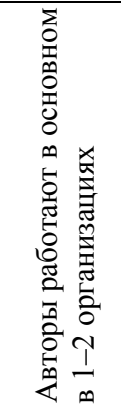 & 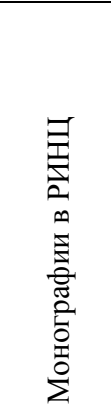 & 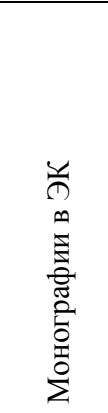 & $\begin{array}{l}\text { J } \\
\text { : } \\
\text { : } \\
0 \\
0 \\
\sum_{0}^{0} \\
0 \\
0 \\
\infty\end{array}$ \\
\hline 1 & Техносфера & 1 & Нет & Да & Да & Да & Нет \\
\hline 2 & Физматлит & 1 & Нет & Да & Нет & Да & Нет \\
\hline 3 & Дальнаука & 1 & Нет & Да/нет & Да & Да & Да/нет \\
\hline 4 & $\begin{array}{l}\text { Научное } \\
\text { обозрение }\end{array}$ & 2 & Да & Нет & Да & Да & Да \\
\hline 5 & $\begin{array}{l}\text { Консалтин- } \\
\text { говая ком- } \\
\text { пания } \\
\text { Юком } \\
\end{array}$ & 2 & Нет & Да & Да & Нет & Да \\
\hline 6 & $\begin{array}{l}\text { Научный } \\
\text { мир }\end{array}$ & 2 & Нет & нет & Да & Да & Нет \\
\hline 7 & $\begin{array}{l}\text { Изд-во } \\
\text { ГПНТБ СО } \\
\text { РАН }\end{array}$ & 3 & Нет & Да & Да/нет & Да & Да /нет \\
\hline 8 & $\begin{array}{l}\text { Изд-во Ин- } \\
\text { та филосо- } \\
\text { фии РАН }\end{array}$ & 3 & Нет & Да & Да/нет & Да/нет & Нет \\
\hline 9 & $\begin{array}{l}\text { Издатель- } \\
\text { ство Ин-та } \\
\text { русской } \\
\text { литературы }\end{array}$ & 3 & Нет & Да & & Да & Нет \\
\hline 10 & НГТУ & 3 & Нет & Да & & Да & Нет \\
\hline
\end{tabular}

${ }_{1}$ «Да/нет» здесь и далее означает, что почти 50 на 50 издание представлено в обоих вариантах. 


\section{Сравнительный анализ коллективных монографий на основе традиционных типологических характеристик}

В данных, представленных в табл. 4, можно выделить только одно издательство, которое резко выделяется на фоне других. Это издательство, которое размещает на своем сайте приглашение авторам присылать свои материалы для издания в формате коллективной монографии. И вторым сопутствующим признаком такой коллективной монографии является совпадение числа авторов с числом организаций, в которых они работают. Также вполне логично, что такого рода монографии представлены в открытом доступе: издательство имеет прибыль не от продажи издания, а от оплаты авторами всего издательского процесса. Последним эти издательства отличаются от традиционных (группа 1), которые имеют прибыль от продажи книг и потому практически не представлены в ОД.

Заметим также, что открытый доступ сам по себе не является гарантией высокого цитирования и показателем высокой информативности. Проведенное сравнение альтметрических данных РИНЦ показало, что наибольшее число цитирований (сравнивались монографии 2014 г.) - 70 получила монография, изданная Физматлитом, не представленная в ОД. Среди монографий, инициируемых «Научным обозрением»и представленных в ОД, самое высокое - 20. При этом у другого издательства той же группы - «Научный мир» - есть в активе монографии, отсутствующие в открытом доступе, но имеющие гораздо большее цитирований, поскольку эти монографии были принесены в издательство коллективом авторов, а не инициированы им.

Что касается количества авторов публикации, заявляемой как коллективная монография, то здесь потребовался наукометрический анализ, позволивший определить наличие или отсутствие научных связей между авторами. На основе данных РИНЦ по 10 монографиям ${ }^{1}$ было определено, есть ли совместные публикации у авторов и социтирования. Еще более точные данные можно было бы получить на основе информации о наличии совместных исследовательских проектов у организаций, где они работают. Это также может помочь отличить действительно коллективную монографию с большим числом авторов от фейковой, подготовленной только ради отчета, и тем более от сборника статей, выдаваемого за коллективную монографию.

Очевидно, что для получения более точных специфических характеристик коллективных монографий необходим тотальный анализ коллективных монографий гораздо большего количества издательств из различных групп. Тем не менее уже сейчас можно попробовать сформировать сравнительную таблицу характеристик коллективных монографий, инициируемых авторами (или исторически сложившегося вида коллектной монографии) и издателями (или издательской коллективной монографии) (табл. 5).

\footnotetext{
${ }^{1}$ Было выбрано по 10 монографий только для того, чтобы все издательства оказались более или менее в равных условиях.
} 


\section{Таблица 5. Сравнительная характеристика}

\begin{tabular}{|c|c|c|c|c|c|}
\hline \multirow[b]{2}{*}{$\begin{array}{l}\text { № } \\
\text { П/ח }\end{array}$} & \multirow[b]{2}{*}{ Характеристика } & \multicolumn{3}{|c|}{$\begin{array}{c}\text { Исторически сложившийся вид коллектной } \\
\text { монографии }\end{array}$} & $\begin{array}{c}\text { Издательская } \\
\text { коллективная } \\
\text { монография }\end{array}$ \\
\hline & & $\begin{array}{c}\text { Издатель - } \\
\text { научное } \\
\text { издательство }\end{array}$ & $\begin{array}{c}\text { Издатель - } \\
\text { новое } \\
\text { коммерческое } \\
\text { издательство }\end{array}$ & $\begin{array}{c}\text { Издатель - } \\
\text { научный } \\
\text { институт, } \\
\text { вуз }\end{array}$ & $\begin{array}{c}\text { Издатель - } \\
\text { новое } \\
\text { коммерческое } \\
\text { издательство }\end{array}$ \\
\hline 1 & $\begin{array}{l}\text { Инициатор } \\
\text { создания } \\
\text { коллективной } \\
\text { монографии } \\
\end{array}$ & \multicolumn{3}{|c|}{$\begin{array}{c}\text { Коллектив сотрудников, работающих над } \\
\text { одной проблемой }\end{array}$} & $\begin{array}{c}\text { Редакция, } \\
\text { определяющая } \\
\text { актуальную } \\
\text { тематику } \\
\end{array}$ \\
\hline 2 & $\begin{array}{l}\text { Средства на } \\
\text { издание }\end{array}$ & \multicolumn{3}{|c|}{$\begin{array}{c}\text { На средства организации, где работают } \\
\text { авторы, гранта }\end{array}$} & $\begin{array}{c}\text { На средства } \\
\text { авторов } \\
\end{array}$ \\
\hline 3 & Формат & Печатный & $\begin{array}{l}\text { Печатный, } \\
\text { электронный }\end{array}$ & $\begin{array}{l}\text { Печатный, } \\
\text { электронный }\end{array}$ & $\begin{array}{l}\text { Печатный, } \\
\text { электронный }\end{array}$ \\
\hline 4 & $\begin{array}{l}\text { Социтирование } \\
\text { и соавторство в } \\
\text { других } \\
\text { публикацих } \\
\end{array}$ & & & & \\
\hline 5 & $\begin{array}{l}\text { Включение в } \\
\text { систему } \\
\text { научных } \\
\text { коммуникаций }\end{array}$ & УДК, ББК & $\begin{array}{l}\text { УДК, ББК, } \\
\text { РИНЦ }\end{array}$ & $\begin{array}{l}\text { УДК, ББК, } \\
\text { РИНЦ }\end{array}$ & $\begin{array}{l}\text { УДК, ББК, } \\
\text { РИНЦ }\end{array}$ \\
\hline 6 & $\begin{array}{l}\text { Выполнение } \\
\text { закона об ОЭ } \\
\text { (наличие } \\
\text { изданя в } \\
\text { библиотеках) }\end{array}$ & Да & Не всегда & Нет & Нет \\
\hline 7 & Рецензирование & Да & Да & Да & Да \\
\hline
\end{tabular}

Как видим, читателю могли бы помочь разобраться, какая коллективная монография перед ним, следующие формальные признаки:

- кто является инициатором подготовки коллективной монографии;

- на какие средства она издается;

- есть ли социтирование и соавторство в других публикацих;

- есть ли книга в фондах библиотек, получающих ОЭ.

Полагаем, то если коллективная монография инициирована издательством, у ее авторов до того не было совместных публикаций или хотя бы социтирований, то к ее научной сущности нужно отнестись хотя бы настороженно.

\section{Заключение}

В уже упоминавшейся работе [3] среди мер, способных вернуть науке научное знание, называлась следующая: «...необходимо начать оказывать финансовую поддержку (на государственном уровне) тем научным издательствам, которые, несмотря на высокую конкуренцию, продолжают публиковать достоверные научные знания» [3. С. 10]. В работе [1] авторы полагают, что ученые должны скоординироваться, «научное сообщество само должно 
быть в состоянии оценивать качество научной работы, минуя посредничество издателя» [1. С. 30].

Предварительный анализ положения дел с коллективными научными монографиями показал, что появились «издательские» коллективные монографии. Как свидетельствует анализ формальных характеристик, некоторые из них могли бы помочь читателю сориентироваться - что за издание перед ним. Особенно это касается монографий по гуманитарным проблемам. Но это может оказаться затратным по времени, поскольку нигде напрямую таких сведений не приводится. Поэтому, как нам представляется, одной из мер, помогающей читателю сориентироваться в уровне публикации, может стать отражение в издательской аннотации информации об инициаторе написания, в рамках какого проекта получены результаты, насколько тесно авторы тематически связаны друг с другом, будет ли книга в фондах библиотек, получающих ОЭ, или ее можно найти в открытом доступе.

Благодарность. Автор выражает благодарность канд. техн. наук зам. директора ООО НЭБ $B . A$. Глухову за обсуждение статьи и высказанные ценные замечания.

\section{Лuтература}

1. Julius Kravjar and Marek Hladík. The ethical hole at the centre of 'publish or perish'// University world press. 30 September 2016 Issue No:430 = Кравиар Ю., Хладик М. Этическая «дыра» в центре научной парадигмы «публикуйся или умри» // Информация и инновации. 2016. № . C. $28-31$.

2. Абрамов Е.Г. Наукометрия - колосс на глиняных ногах // Информация и инновации. 2016. № 1. C. 12-14.

3. Угринович E.B. Прогресс и регресс, или Как вернуть в научные издания научное знание? / Е.В. Угринович, Д.В. Мун, В.В. Попета // Информация и инновации. 2016. № 1. С. 4-11.

4. Почему было принято решение об исключении группы журналов из PИНЦ? URL: https://elibrary.ru/retraction_faq.asp (дата обращения: 19.07.2017).

5. Лаврик О.Л. Коммерческие научные издания как дань времени // Книга : Сибирь - Евразия: Тр. 1-го Междунар. науч. конгресса: в 3 т. Новосибирск, 2016. Т. 3. С. 129-136.

6. Лаврик О.Л. Материалы заочных конференций как средство научных коммуникаций // Вестн. Том. гос. ун-та. Культурология и искусствоведение. 2016. № 4 (24). С. 234-239.

7. Лаврик О.Л. Новый вид политематических научных сборников в печатном формате: назначение, структура, условия существования в системе научных коммуникаций // Десятые Макушинские чтения : материалы науч. конф., Томск, 12-14 мая 2015 г. Новосибирск, 2015. C. $164-168$.

8. Лаврик О.Л. Новые средства научных коммуникаций и их влияние на формирование ресурсов академических библиотек / О.Л. Лаврик, Н.И. Подкрытова // Вестн. Том. гос. ун-та. Культурология и искусствоведение. 2015. № 1 (17). С. 99-103.

9. Васильев В.И. Издательская деятельность Академии наук в ее историческом развитии: в 2 кн. М., 1999.

10. Черняк А.Я. История технической книги: учеб. М.: Книга, 1981.318 с.

11. Монография. URL: https://ru.wikipedia.org/wiki/\%D0\%9C\%D0\%BE\%D0\%BD\% $\mathrm{D} 0 \% \mathrm{BE} \% \mathrm{D} 0 \% \mathrm{~B} 3 \% \mathrm{D} 1 \% 80 \% \mathrm{D} 0 \% \mathrm{~B} 0 \% \mathrm{D} 1 \% 84 \% \mathrm{D} 0 \% \mathrm{~B} 8 \% \mathrm{D} 1 \% 8 \mathrm{~F}$ (дата обращения: 19.07.2017).

12. Источники научной информации. URL: http://lib.znate.ru/docs/index-229228.html (дата обращения: 19.07.2017).

13. Цветкова В.А. Книга в научных исследованиях / В.А. Цветкова, Е.В. Кочукова, Н.И. Подкорытова, Д.А. Третьяков // Информация и инновации. 2016. № . 1. С. 20-28.

Lavrik Olga L. State Public Scientific-Technological Library of the Siberian Branch of the Russian Academy of Sciences (Novosibirsk, Russian Federation). 
E-mail: Lavrik@spsl.nsc.ru

Tomsk State University Journal of Cultural Studies and Art History, 2017, № 28, pp. 213-224. DOI: $10.17223 / 22220836 / 28 / 21$

\section{COLLECTIVE MONOGRAPH: ATTEMPT FOR A FORMALIZED EVALUATION OF SCIENTIFIC VALUES}

Key words: collective monograph, formal characteristics, publishing houses, publishing collective monograph, co-authorship, co-citation, open access, legal deposit.

The problem of reducing the quality of scientific publications in recent years has been more and more actively discussed in professional literature. If in case of journal publication, one can immediately identify spam features basing on such characteristics as payment for the publication of an article and a very rapid publication (i.e., the actual lack of reviewing) then in case of monographs it is not so obvious. The question arises: what formal parameters could be used by an expert reader, a librarian, an information worker to judge about it? We assume that a collective monograph (a scientific book) is a scholar work reflecting research results of theoretical, applied, methodological or predictive nature, conducted by a team of researchers working in one institution or temporary research group according to a pre-established program of research.

The following hypothesis was tested: formal distinctions between a true scientific collective monograph and such, not carrying new scientific knowledge should be sought on the basis of a comparison of the following pairs of characteristics: 1) a publisher does not invite (invites) authors to send materials for publishing a collective monograph in the framework of a given theme; 2) the authors work in one, two, or a large number of institutions; 3) the authors of the collective monograph work (do not work) on one project (program); 4) the authors have (have not) a joint publication and refer (do not refer) to each other; 5) the monograph can (cannot) be found in the open access; 6) Monographs are (are not) in the libraries receiving the Legal Deposit (reflected in electronic catalogues). To test the hypothesis collective scientific monographs (written by more than two authors) published in 2013 - 2026 were chosen. They were issued by three different types of publishers: 1) scientific publishers, having a good scientific reputation; 2) publishers, "established" themselves by publishing spam journals; 3) research institutions and universities having printing base. To obtain the necessary characteristics sites of publishing houses and publishing organizations were also analysed, searches in RISC and SPSL SB RAS electronic catalogues were made, substantial analysis of publishing annotations was performed.

The analysis showed that a reader could recognize a collective monograph of low quality, if he knew:

-who is the initiator of the collective monograph (a publisher);

- on what means it is published (authors' means); absent).

- is there co-citation and co-authorship in other publications (co-citaion and co-authorship are

This information would have to be reflected in a publishing annotation.

\section{References}

1. Kravjar, J. \& Hladík, M. (2016) The ethical hole at the centre of 'publish or perish'. University World Press. 30th September.

2. Abramov, E.G. (2016) Naukometriya - koloss na glinyanykh nogakh [Scientometrics - a colossus on clay feet]. Informatsiya i innovatsii. 1. pp. $12-14$.

3. Ugrinovich, E.V., Mun, D.V. \& Popeta, V.V. (2016) Progress i regress, ili Kak vernut' v nauchnye izdaniya nauchnoe znanie? [Progress and regress, or How to return scientific knowledge to scientific publications?]. Informatsiya i innovatsii. 1. pp. 4-11.

4. Elibrary.ru. (n.d.) Pochemu bylo prinyato reshenie ob isklyuchenii gruppy zhurnalov iz RINTs? [Why it was decided to exclude a group of journals from the RISC?]. [Online] Available from: https://elibrary.ru/retraction_faq.asp. (Accessed: 19th July 2017).

5. Lavrik, O.L. (2016) Kommercheskie nauchnye izdaniya kak dan' vremeni [Commercial scientific publications as a tribute to the time]. Kniga: Sibir' - Evraziya [Book: Siberia - Eurasia]. Proc. of the First International Congress. Novosibirsk. pp. 129-136.

6. Lavrik, O.L. (2016) Materials of correspondence conferences as a means of scientific communication. Vestnik Tomskogo gosudarstvennogo universiteta. Kul'turologiya i iskusstvovedenie - Tomsk 
State University Journal of Cultural Studies and Art History. 4(24). pp. 234-239. (In Russian). DOI: $10.17223 / 22220836 / 24 / 26$

7. Lavrik, O.L. (2015) [A new kind of polytematic scientific collections in printed format: the purpose, structure, conditions of existence in the system of scientific communications]. Desyatye Makushinskie chteniya [Tenth Makushin Readings]. Proc. of the Conference. Tomsk. May 12-14, 2015. Novosibirsk. pp. 164-168. (In Russian).

8. Lavrik, O.L. \& Podkrytova, N.I. (2015) New means of scholar communication and their impact on research libraries resources formation. Vestnik Tomskogo gosudarstvennogo universiteta. Kul'turologiya i iskusstvovedenie - Tomsk State University Journal of Cultural Studies and Art History. 1(17). pp. 99-103. (In Russian). DOI 10.17223/22220836/17/16

9. Vasiliev, V.I. (1981) Izdatel'skaya deyatel'nost' Akademii nauk v ee istoricheskom razvitii: $v 2$ $k n$. [The publishing activity of the Academy of Sciences in its historical development: in 2 books]. Moscow: [s.n.].

10. Chernyak, A.Ya. (1981) Istoriya tekhnicheskoy knigi [History of the technical book]. Moscow: Kniga.

11. Wikipediya. (n.d.) Monografiya [Monograph]. [Online] Available from: https://ru.wikipedia.org/wiki/\%D0\%9C\%D0\%BE\%D0\%BD\%

D0\%BE\%D0\%B3\%D1\%80\%D0\%B0\%D1\%84\%D0\%B8\%D1\%8F. (Accessed: 19th July 2017).

12. Lib.znate.ru. (n.d.) Istochniki nauchnoy informatsii [Sources of scientific information]. [Online] Available from: http://lib.znate.ru/docs/index-229228.html. (Accessed: 19th July 2017).

13. Tsvetkova, V.A., Kochukova, E.V., Podkorytova, N.I. \& Tretyakov, D.A. (2016) Kniga v nauchnykh issledovaniyakh [Book in Scientific Research]. Informatsiya i innovatsii. 1. pp. 20-28. 